\title{
International Space Station Crew Quarters Ventilation and Acoustic Design Implementation
}

\author{
James L. Broyan, Jr. ${ }^{1}$ \\ NASA Lyndon B. Johnson Space Center, Houston, TX, 77058 \\ Scott M. Cady ${ }^{2}$ \\ GeoControl Systems, Inc., Houston, TX, 77058 \\ and \\ David A. Welsh ${ }^{3}$ \\ MEI Technologies, Inc., Houston, TX 77058
}

\begin{abstract}
The International Space Station (ISS) United States Operational Segment has four permanent rack sized ISS Crew Quarters (CQs) providing a private crew member space. The CQs use Node 2 cabin air for ventilation/thermal cooling, as opposed to conditioned ducted air from the ISS Common Cabin Air Assembly (CCAA) or the ISS fluid cooling loop. Consequently, CQ can only increase the air flow rate to reduce the temperature delta between the cabin and the CQ interior. However, increasing airflow causes increased acoustic noise so efficient airflow distribution is an important design parameter. The CQ utilized a two fan push-pull configuration to ensure fresh air at the crew member's head position and reduce acoustic exposure. The $C Q$ ventilation ducts are conduits to the louder Node 2 cabin aisle way which required significant acoustic mitigation controls. The CQ interior needs to be below noise criteria curve 40 (NC-40). The design implementation of the CQ ventilation system and acoustic mitigation are very inter-related and require consideration of crew comfort balanced with use of interior habitable volume, accommodation of fan failures, and possible crew uses that impact ventilation and acoustic performance. Each CQ required $\sim \mathbf{1 3 \%}$ of its total volume and $\sim 6 \%$ of its total mass to reduce acoustic noise. This paper illustrates the types of model analysis, assumptions, vehicle interactions, and trade-offs required for $\mathrm{CQ}$ ventilation and acoustics. Additionally, on-orbit ventilation system performance and initial crew feedback is presented. This approach is applicable to any private enclosed space that the crew will occupy.
\end{abstract}

\section{Nomenclature}

$\begin{array}{ll}\mathrm{CCAA} & =\text { Common Cabin Air Assembly } \\ C O_{2} & =\text { Carbon Dioxide } \\ C Q & =\text { Crew Quarter } \\ d B & =\text { decibel } \\ d B A & =\text { decibel A-weighted } \\ J S C & =\text { Johnson Space Center } \\ \mathrm{Hz} & =\text { Hertz } \\ I S S & =\text { International Space Station } \\ N C & =\text { Noise criterion curve } \\ T e S S & =\text { Temporary Sleep Station }\end{array}$

\footnotetext{
${ }^{1}$ Habitability Hardware Group Lead, Crew \& Thermal Systems Division, M/S: EC3, not AIAA affiliated.

${ }^{2}$ Deputy Division Chief Engineer, Structural Engineering Division, M/S: ES1, not AIAA affiliated.

${ }^{3}$ Senior Acoustics Engineer, JSC Acoustics Office, M/S: SF22, not AIAA affiliated.
} 


\section{Introduction}

After the launch of shuttle assembly flight STS-131 (19A) in April 2010, the International Space Station (ISS) will contain the full complement of four Crew Quarters (CQs). The CQs are located the four bay 5 locations of Node 2 and form a ring. Overviews of the general architectural layout of CQ and the general tradeoffs during its development have been previously described ${ }^{1,2}$. A brief overview of the layout is necessary prior to a more detailed discussion of the acoustical challenges addressed by the CQ design.

Functionally a CQ provides an acoustically quiet and visually isolated area in which crew members can sleep, relax, and retreat to a private area. The ISS volume allocated to a CQ is a standard ISS rack volume with two protrusions, shown in Fig. 1. Approximately $8 \mathrm{~cm}$ of additional head room is provided with a deployable ceiling called a pop-up. The pop-up is integral to the CQ rack and deployed once the CQ rack is installed. In the on-orbit deployed configuration, a 30-cm protrusion called the bump-out, extends into the Node 2 aisle way. This volume provides no direct habitable for the crew, with the exception of the door passage. As will be described, the bump-out volume was allocated to the ventilation system.

The total deployed volume of CQ is $\sim 2.1 \mathrm{~m}^{3}$ and it was desirable to provide as large a habitable volume for the crew member as possible. This presented a design challenge to provide adequate air flow, minimize fan generated noise, and reduce exterior noise transmitted into the CQ interior.
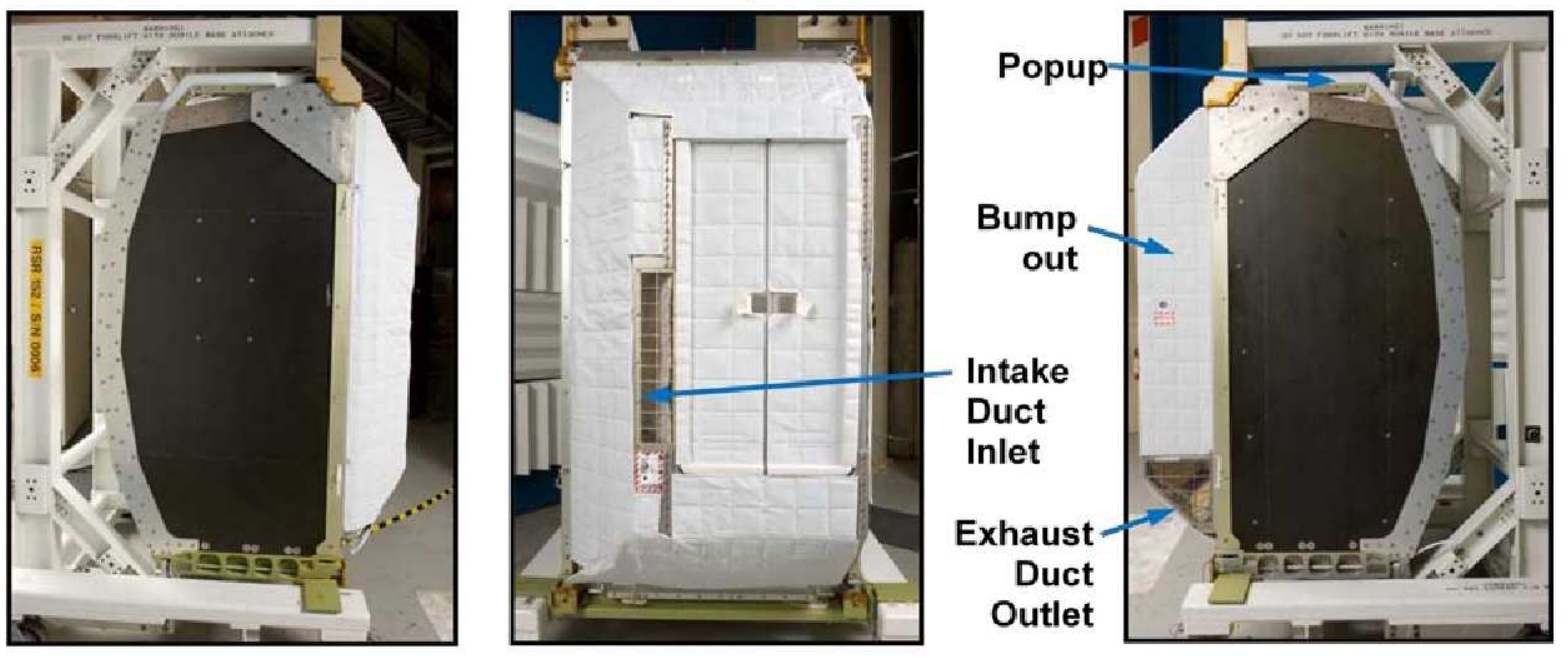

Figure 1. Port/Deck CQ on-orbit configuration in a rack handling adapter (white tubular structure), external views (left to right): forward side, front side - toward aisle way, and aft side.

\section{Ventilation/Acoustic Architecture}

The physical and operational considerations of the CQ ventilation and acoustics architecture were determined at several levels. Operationally at the vehicle level, the Node 2 Common Cabin Air Assembly (CCAA) can be adjusted to reduce the ISS aisle way temperature to $\sim 18^{\circ} \mathrm{C}$. Since the aisle way air temperature can be controlled, the CQs were not provided interfaces to the ISS coolant loops. This required the CQs to utilize air exchange with the aisle way to provide crew comfort. Each CQ draws in aisle way air perpendicular to the rack face through an intake duct inlet, shown in Fig. 1. The air is circulated through the CQ volume by two fans. Inside the CQ, the air adsorbs the crew member's metabolic heat (100-132 watts) and the electronics waste heat ( 153 watts). The air is then directed though the CQ exhaust duct outlet, see Fig. 1, and directed parallel to the rack face and down the aisle way toward the Node 2 CCAA air return. These CQ air intake and exhaust directions are consistent with the general Node 2 air circulation which allows the CCAA smoke detector to identify combustion events within the CQ. Additionally, these intake and exhaust directions minimize recirculation of air between CQs which would result in some CQ interiors not receiving adequate cooling. The primary vehicle level interface ventilation requirements for the $\mathrm{CQ}$ are:

- $\quad 0.42-5.1 \mathrm{~m}^{3} / \mathrm{min}$ of airflow.

- $\quad<76 \mathrm{~m} / \mathrm{min}$ exhaust air velocity.

At the vehicle level, all the CQs are physically located in one area, Node 2, bay 5 . Node 2 is at one end of ISS so there is less crew translation which can impart impulse noise and moderate vibration to the CQ interior. 
Additionally, Node 2 provides a lower acoustic environment because the remaining four rack bays are relatively quite electrical power converter racks. The primary vehicle level interface acoustic requirements for the $\mathrm{CQ}$ are:

- CQ interior between noise criterion (NC) curves 25 and 40.

- External noise environment in Node 2 aisle way of NC curve 52.

- CQ exterior acoustic emissions of NC curve 40 .

It was acknowledged at the beginning of the CQ project that ventilation and acoustics were the primary functional requirements and would be the most challenging to satisfy. If the CQ ventilation (quantity and control) was inadequate for crew comfortable, they would not use it. If the CQ interior was not sufficiently quiet, the crew would need hearing protection or sleep medications - both of which are unacceptable for long term use. Additionally, the ventilation system removes carbon dioxide which is an asphyxiation hazard. The asphyxiation hazard is categorized as a catastrophic hazard and required redundancy.

The CQ project addressed these vehicle interface requirements by decomposing them into three primary hardware systems: fans, ducts, and structure/blankets. These three areas are interrelated and were developed in parallel to meet the hardware delivery schedule constraints. Figure 2 illustrates the location of all the bump-out features that are accessible to the crew when inside the CQ without the acoustic blankets. The acoustic blankets are not shown but attach to the structure with hook and loop fastener patches. In Fig. 2 the CQ is in the launch configuration where the bump-out is reversed and mounted to rack front so there is no aisle way protrusion.

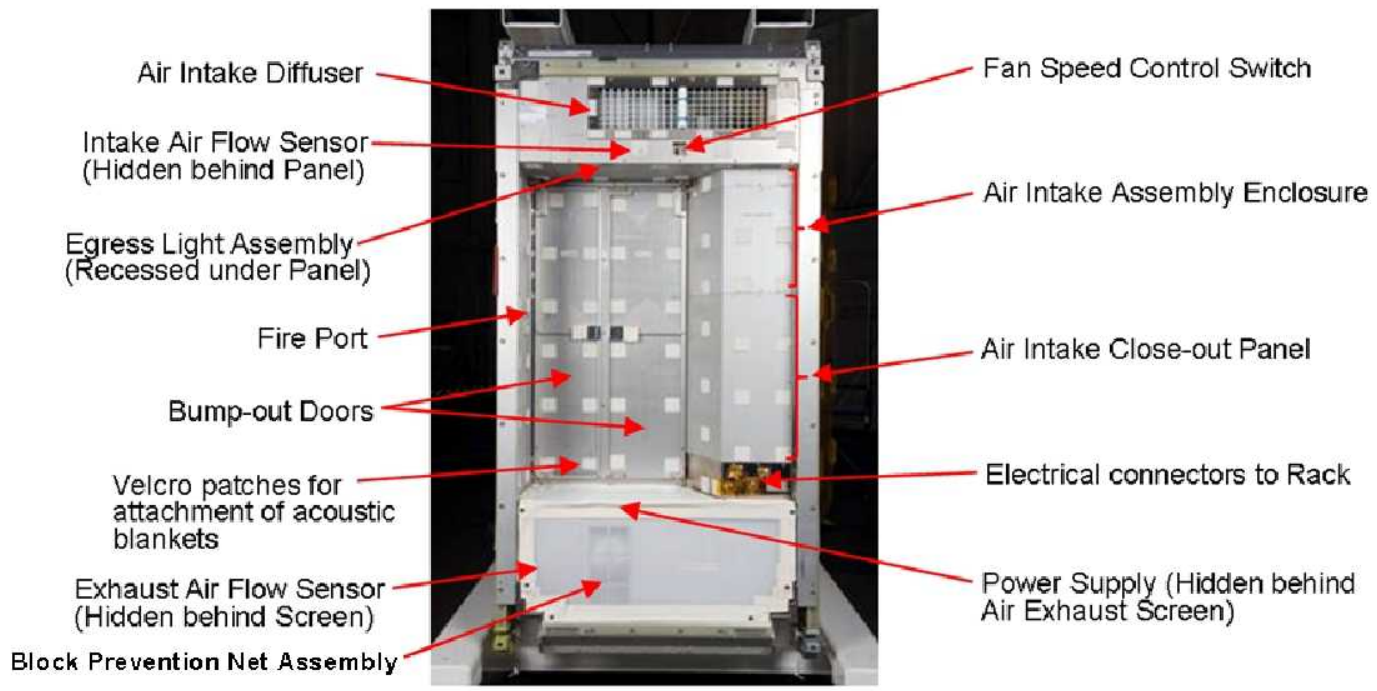

Figure 2. Port/Deck CQ in the launch configuration.

Figure 3 illustrates the interior of the CQ bump-out in the on-orbit deployed position. In this configuration the white interior acoustic blankets cover most surfaces to reduce acoustic noise transmitted from the ISS aisle way. In the deployed configuration, it is difficult to obtain a single full height view of the bump-out. The general layout and air flow of the intake duct layout and exhaust duct layout and air flow are depicted in Figs. 4 and 5 respectively. The red line represents the air flow path. These shapes and features will be described greater detail in the following sections.

\section{A. Fan Architecture}

Two fans per CQ were required to prevent a single point failure (complex implementations of redundant motor windings and internal sensors were not considered due to schedule constraints). Both serial and parallel implementations of the dual fan system were investigated as possible solutions. Several characteristics were compared; including: power efficiency, pressure head capability, packaging, acoustic interactions, and failure modes. A standard $90 \mathrm{~mm}$ fan was the largest common sized fan that could be packaged in each duct.

The serial fan configuration has one fan downstream of the first fan. The fans can be physically mounted in separate ducts but connected by the CQ interior volume. This configuration allows each fan to add its head pressure capability to move the single column of air through the ducting; thereby allowing the system to operate at a higher pressure head for a given flow rate. The fan pressure head is required to overcome the back pressure (pressure loss) generated by the ventilation ducts' length and number of bends. 


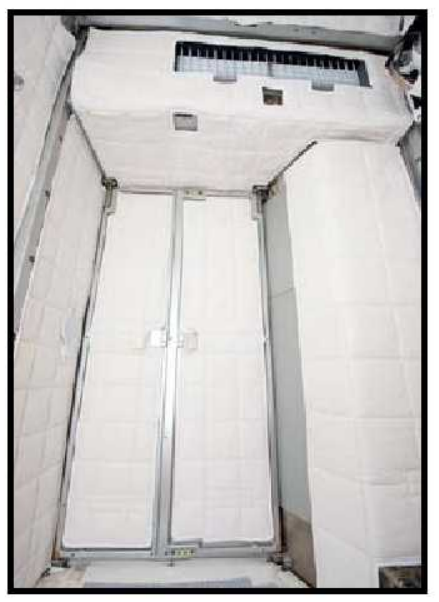

Figure 3. Port/Deck CQ interior in the on-orbit deployed configuration.

The parallel fan configuration has two fans side by side or in parallel ducts of equal pressure drop. The fans can be physically separated into separate parallel ducts of equal back pressure. This configuration allows each fan a higher flow rate for a given pressure head. Figure 5 shows the comparison of a single CQ fan, two CQ fans in series, and two CQ fans in parallel.

As will be discussed in the 'duct acoustic considerations' section later, the ducting required numerous bends and abatements to reduce acoustic noise from the ISS aisle way and the CQ fans themselves. The CQ ducts' backpressure and is represented in Fig. 5 as the black system curve. In the serial configuration, one fan can be near the crew's head and the other near their feet. This requires less duct volume near the crew's head and increases the CQ's perceived interior volume. In the parallel configuration, both fans (or at least the duct outlets) must be near the crew's head. This is required to provide the coolest air to the crew's head and to ensure $\mathrm{CO}_{2}$ removal when the $\mathrm{CQ}$ door is open. This requires increased duct volume near the crew's head and decreases the CQ's perceived interior volume. Additionally, the parallel fan configuration also requires an isolation damper prevent back flow out the duct if one fan failed.

In addition to the crew head duct volume advantage, the point of intersection between the system curve and either the serial fan curve or the parallel fan curves of Fig. 5 illustrates the differences in flow. The serial fan configuration can provide $2.7 \mathrm{~m}^{3} / \mathrm{min}$ of airflow and is in an area of stable fan performance. Whereas, the parallel fan configuration provides $2.1 \mathrm{~m}^{3} / \mathrm{min}$, and is in an area of potentially unstable fan performance (relatively flat region of curve). This unstable region of the parallel fan curve could result in acoustical oscillations from fan/duct backpressure interactions.

Based on the reduced duct volume at the crew head and the increased airflow rate at higher duct backpressures, the serial fan configuration was selected. The calculated flow/backpressure requirements combined with acoustical considerations enabled the number of commercially available fans to be narrowed. The JSC Acoustics Office assisted in developing an acoustics plan and evaluating candidate fans. The following general guidelines were used narrowing fan selection:

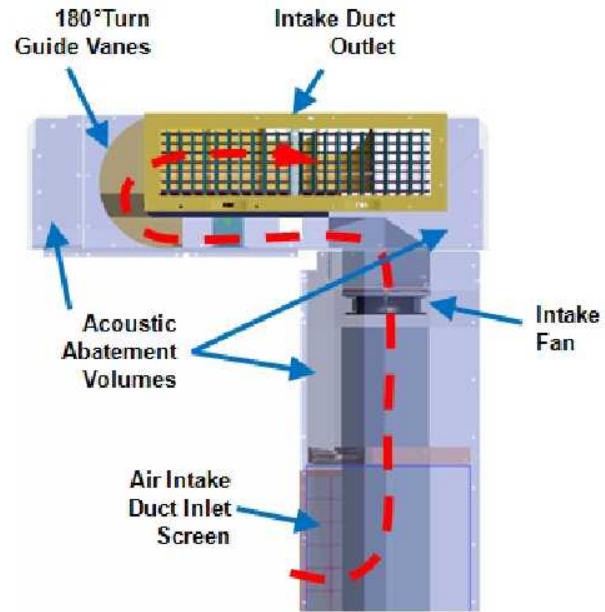
dedicated to abatements.

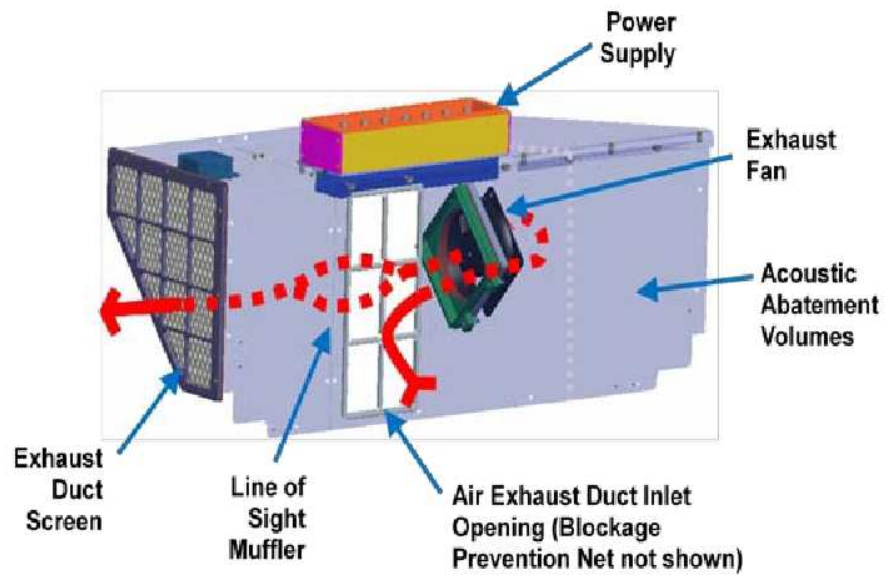

Figure 5. Exhaust duct ventilation flow path and volume dedicated to abatements.
Figure 4. Intake duct ventilation flow path and volume 


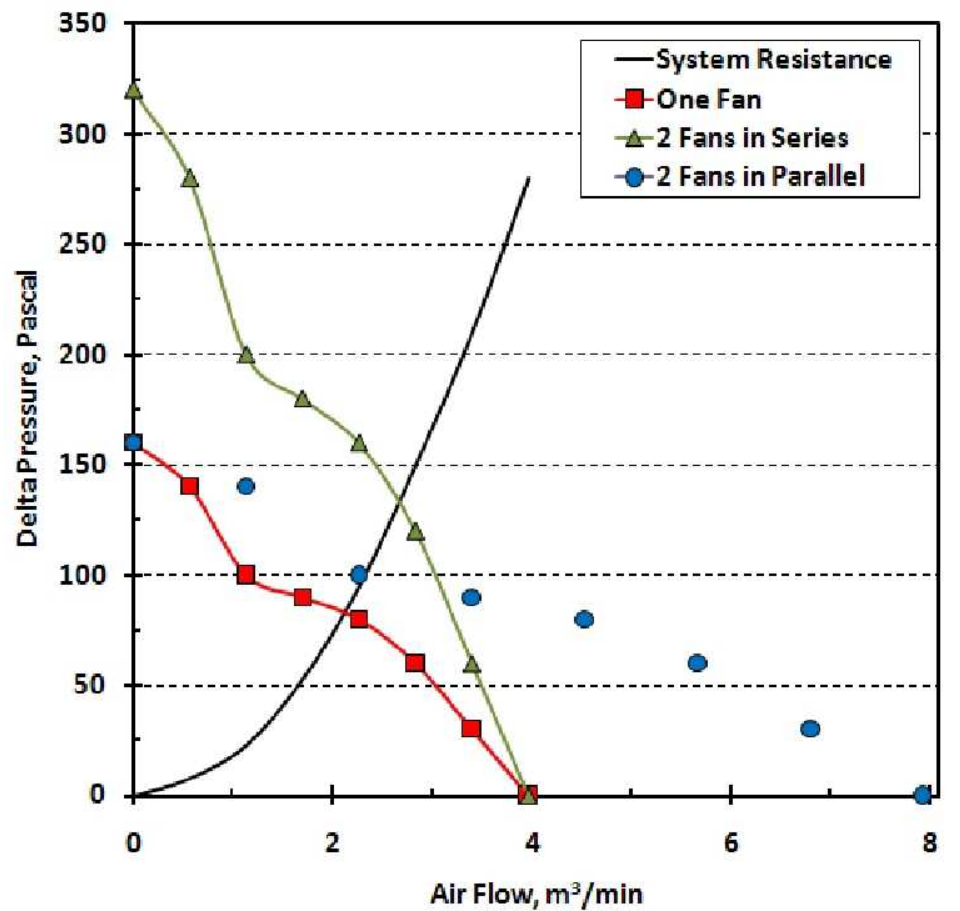

Figure 5. CQ fan performance for single, serial, and parallel configurations.

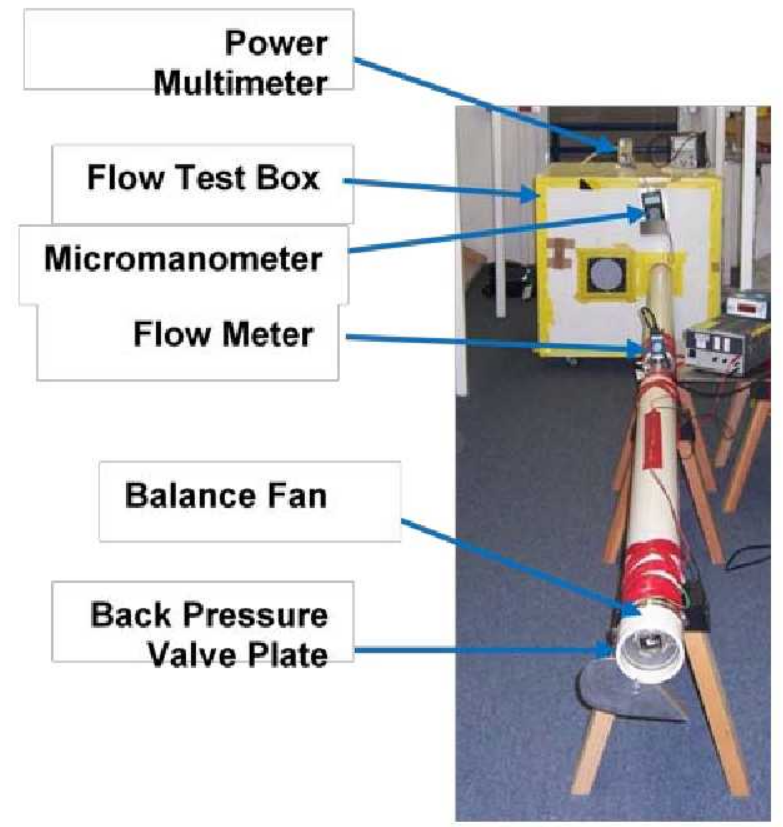

Figure 6. CQ fan flow performance test stand.
- Fans with more fan blades are generally quieter because the blade loading decreases.

- Generally fans with plastic blades are quieter than metal fan blades.

- Lower fan rotational speeds are generally quieter.

- Locate fans away from surface panels. This helps to avoid turbulent air flow, which causes greater noise.

- Design ducting which muffles and absorbs noise.

- Keep flow paths smooth.

Commercial fans were reviewed but generally only fans used in previous military or aerospace applications had acceptable motor and drive electronics. The largest fan frame size, $90 \mathrm{~mm}$, which could be reasonable packaged in the CQ duct volume was selected to allow it to operate at lower speeds. However, most fans in this size range were optimized for higher flow and back pressure, required more electrical power, and generated more acoustical noise than acceptable to the CQ project. The JSC Acoustics Office was in the process of generating a database of sound characteristics of commercially available fans and recommended five fans for testing. Each fan was mounted in a simple test stand that allowed for varying the backpressure to determine the actual flow rate, power draw, and acoustic signature, Fig. 6. Most fan manufacturer acoustic data is for operation in free air without backpressure. As a fan is subjected to backpressure the acoustic noise can increase significantly. For the CQ application, testing resulted in the selection of an EBM-Papst $4184 \mathrm{~N} / 2 \mathrm{XH}$ fan as the best compromise between power, flow rate, pressure, size and acoustics. The fan also contained a tachometer to monitor rotational speed which was used as part of the CQ fault detection.

\section{Fan Operation versus Thermal Loads}

Since the CQ is cooled by air exchange with the ISS aisle way, increasing the air flow rate by increasing the fan speed decreases the temperate increase (delta) with the aisle way. For flows above approximately 2.4 $\mathrm{m}^{3} / \mathrm{min}$ there is little additional cooling, see Fig. 7. As air flow increases, fan generated noise and duct aeronoise increase. This resulted in the CQ maximum

fan speed setting to be limited to generate $2.6 \mathrm{~m}^{3} / \mathrm{min}$. The fan speed was set at three speeds: low $\left(1.8 \mathrm{~m}^{3} / \mathrm{min}\right)$, medium $\left(2.3 \mathrm{~m}^{3} / \mathrm{min}\right)$, and high $\left(2.6 \mathrm{~m}^{3} / \mathrm{min}\right)$. Continuous speed control while feasible, introduces less reliable/more complex electrical components with the air speeds not changing perceptively $(\sim 1.8$ to $5.5 \mathrm{~km} / \mathrm{hr})$. Details of the thermal loads were previous described ${ }^{1}$. 


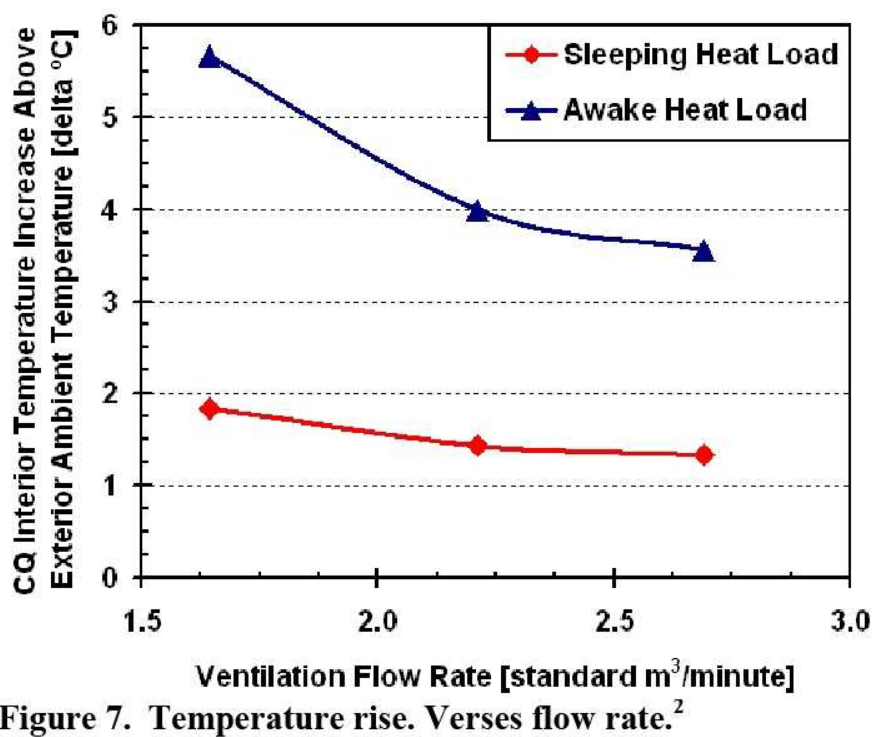

Figure 7. Temperature rise. Verses flow rate. ${ }^{2}$

\section{B. Duct Architecture}

The system curve, Fig. 5, increases rather rapidly due to the number of bends and the volume limits of the CQ bump-out which limited the effective duct diameter. Although the duct shape changes several times to fit in the volume around the doorway, the duct cross sectional area is maintained at $\sim 120 \mathrm{~cm}^{2}$. The serial fan configuration allowed one duct at the crew head position, named the 'intake duct', to transfer air from the ISS aisle way to the CQ interior. The duct at the crew foot potion, named the 'exhaust duct' transfers air from the CQ interior to the ISS aisle way. When the CQ door is opened each fan/duct system works independently because air can short circuit through the door. Another benefit to the serial fan/duct configuration is that it allowed the CQ power supply to be mounted downstream of the CQ interior environment so that the electronics could stay cool while rejecting the $\sim 17$ watts into

air after the air exits the CQ habitable volume. This resulted in a decrease in interior air temperature of $\sim 0.6^{\circ} \mathrm{C}$ or the equivalent of 0.4 to $0.7 \mathrm{~m}^{3} / \mathrm{min}$ of airflow due to the relatively flat curves of Fig. 7 .

The CQ ducts not only direct air but also must adsorb fan generated noise and reduce the noise transmitted from the exterior. Conventional rigid ducting would direct the NC-52 aisle way noise into the CQ interior and easily exceed the NC-40 requirement. The ventilation system could not protrude into the CQ rack volume because of system level trade studies indicated the best manifest/crew deployment configuration for the bump-out was to be removed and reversed to fit completely flush with the rack volume as a single unit for launch. Additionally, this provided structural rigidity during launch and reduced crew time during assembly. The total bump-out volume is $\sim 0.39 \mathrm{~m}^{3}$. The door size of the previous Temporary Sleep Station (TeSS) ${ }^{1}$ was maintained and this translation area was maintained through the bump-out depth. The door volume utilized $\sim 50 \%\left(\sim 0.19 \mathrm{~m}^{3}\right)$ of the bump-out volume and provides additional interior crew volume in the elbow/torso area - which is useful when using the laptop table or changing clothing. This allowed the maximum interior crew volume. Greater duct volume was allocated to the inlet duct, $\sim 34 \%$ of the bump-out volume $\left(\sim 0.13 \mathrm{~m}^{3}\right)$, because the outlet is at the crew head position. The volume shape was complex, running along the forward edge of the door, and between the top of the door and upper bump-out chamfer. The exhaust duct volume, $\sim 11 \%$ of the bump-out volume $\left(\sim 0.04 \mathrm{~m}^{3}\right)$, was located below the door and the lower bump-out chamfer. The remaining bump-out volume was used for structure and miscellaneous hardware.

\section{Duct Acoustic Abatement Considerations}

The interior of the duct surfaces needed to be covered with sound adsorbing material that was acoustically porous, adsorb a wide range of acoustic frequencies, have low frangible (particle generation), cleanable, replaceable, and meet the ISS flammability and mold/fungus resistance standards. Extensive configurations of foams, fills, coverings, and stiffening materials were tested with the assistance of the JSC Acoustic Office. The final flight abatement design consisted of 19 foam blocks and fabric blankets for the CQ duct surfaces. The integrated abatement shapes provided a smooth flow surface and utilize all the remaining bump-out volume. The inlet flow path directs air around three 90 turns and one 180 turn. The intake fan was located close to the front of the duct to allow more opportunities for adsorption before entering the CQ interior. The exhaust flow path provided one 90 degree turn, one 180 degree turn and one muffler region. The depth of the foam at each turn was varied to tailor each area for a particular acoustic noise half-wave length. Several functional duct mocks were used to develop the abatement implementation. 


\section{Duct Mockup Acoustic Tests}

In addition to the mockups used for crew evaluations ${ }^{1}$, the project created a series of full scale ducts early in the development phase. These full scale units were required to characterize the competing requirements of power draw, heat rejection for crew comfort/electrical cooling, sound level requirements, packaging limitations, and manufacturability concerns. The first unit had a wood structure and melamine foam abatements to line the flow path and attenuate the sound levels. The benefit of the wooden mock-up was the ability to easily reconfigure it with multiple abatement materials. This enabled abatements to be tailor to the adsorbed acoustic frequencies of the fan and external environment. The initial duct test stands were comprised of separate intake and exhaust duct structures to evaluate individual duct performance Fig. 8 and Fig. 9.

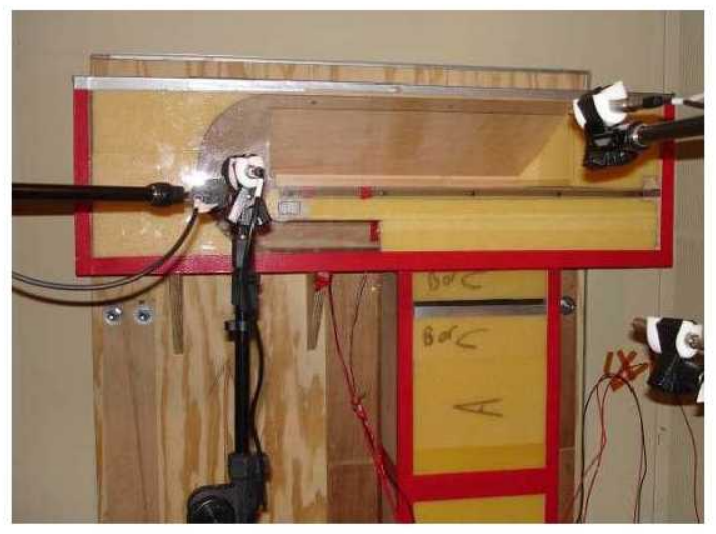

Figure 8. Initial functional intake duct (wood and melamine) in acoustic testing.

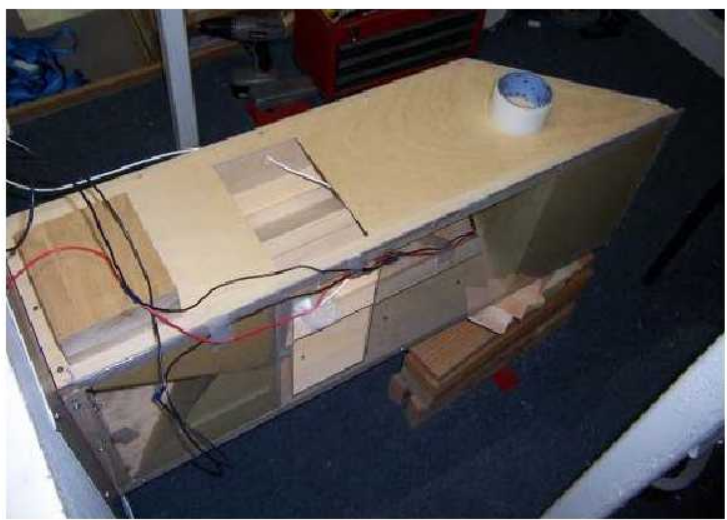

Figure 9. Initial functional exhaust duct (wood and melamine) functional mockup.

The wooden test unit was used to measure CQ specific initial design data for: fan placement within the ducts, system backpressure, flow rate assessments, and rough acoustic measurements. The initial fan and flow testing allowed determination of fan rotational speeds, initial placements of flow sensors, and back pressure of abatement lined ducts. The second round of testing with the wooden test articles was to improve acoustic sensitivity fidelity of fan placement in the duct. In Fig. 8 the horizontal aluminum plate in between the yellow melamine abatements held the intake fan. The intake fan position was adjusted vertically to characterize its effect on acoustic levels. Similar testing was done to the exhaust duct fan placement. The third round of testing investigated placement of airflow sensors and flow distribution at the duct outlets. The airflow sensors function similar to a hotwire anemometer. The sensor heats an area of its surface and the airflow across the sensor cools it down. The sensor compares the ambient temperature and the current temperature of the heated area and evaluates it against the heated area's theoretical temperature without airflow. The sensor provides a voltage output proportional to the change in the air flow across the heated area. With the many turns in the ducting, it was difficult to find a location that provided a consistent representative air speed for flow monitoring. Eventually, the intake duct geometry was slightly altered to place the flow sensor in a narrower cross sectional area that provided more uniform airspeed changes with changing flow rate. Similarly the exhaust flow sensor was moved to the highest air speed location of the divergent zone. Moving both

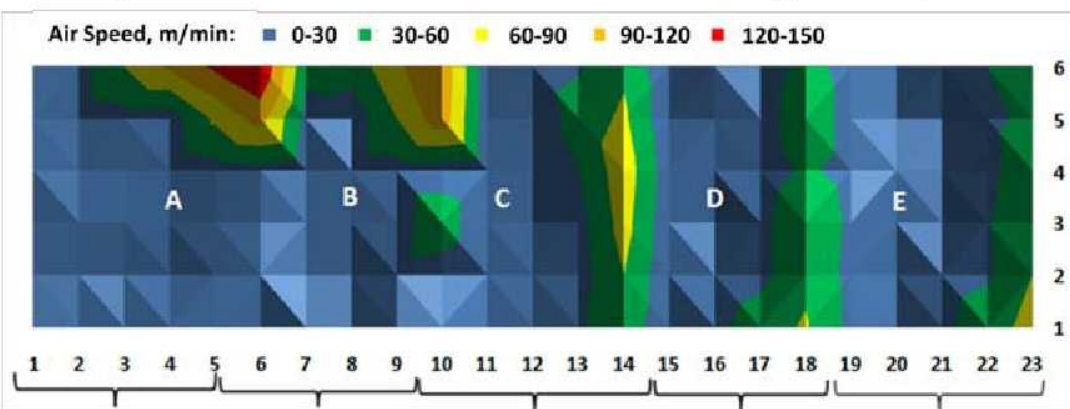

Figure 10. Air speed at each opening in air diffuser outlet after addition of flow vanes to create five air channels (A through $E$ ). flow sensors to higher airspeed regions was required because testing revealed that ducting areas with low air speeds did not change sufficiently during fan/duct failure scenarios. During detailed airspeed measurements of the intake duct outlet, it was discovered that the centrifugal effects of the duct bends was larger than expected, see Fig. 10 (zone E). The majority of the air flow was forced to one end of the intake duct outlet diffuser. A five channel set of guide vanes were

I 
added to more evenly divide the airflow across the diffuser. Figure 10 is the result of 138 hot wire anemometer readings at each intervane opening in the intake duct outlet diffuser (see Fig. 2 and Fig. 4). The letters A through E represent the channels between the guide vanes.

\section{Flight-like Duct Abatement Tests}

As previously discussed ${ }^{1}$ a full scale mid-fidelity mockup was used for crew evaluations. This mockup structure was fabricated from aluminum and composites similar to the flight unit. Additionally, flight-like acoustic blankets and duct abatements were used to test the integrated acoustic mitigation's effectiveness. Several abatements required minor adjustments for proper fit. Testing revealed the intake duct fan's elastomeric mounts did not properly isolate the fan and resulted in structural noise transmission. The design solution was to capture the fan within one of the foam abatements, see Fig 11. This soft capture approach reduced the structure transmitted noise but could possibly damage the abatement during launch so the fan was launch separately and installed on orbit. Additionally the midfidelity mockup revealed a slight acoustic interaction between the intake and exhaust fans. Inside the CQ interior, the fan interaction caused a slight periodic 'beating.' The design solution was to change the electrical drive circuit to reduce the exhaust fan speed $\sim 10$ rotations per minute to remove the beating. Testing indicated that there was likely going to be a minor exceedance near the fan blade pass frequency. Several minor abatement adjustments were incorporated into the final design to reduce the exceedance.

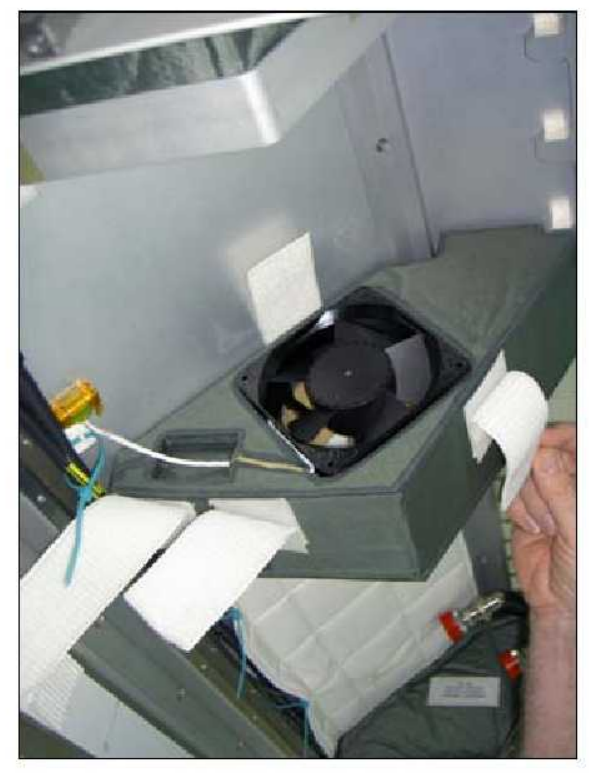

Figure 11. Intake fan soft captured in foam abatement.

\section{Structure Transmitted Acoustic Architecture}

If the ISS ventilation equipment and payload mounted fans/pumps met their acoustic requirements the need for mitigating structure transmitted noise would be greatly reduced. There is a great need for the development of inherently quite fans and pumps to reduce mass dedicated to passive acoustical controls. In addition to the noise generated by the CQ fans and conducted through the ventilation ducts, the ISS aisle way noise (NC-52) is also transmitted through the structure. Candidate materials were tested for their acoustic transmission losses from 63 to $10,000 \mathrm{~Hz}$. Larger transmission losses indicate greater absorbance of sound energy.

\section{Structural Materials}

The CQ racks were constructed of an aluminum frame that captured panels of composite (black material in Fig. 1) or plastic material. The aft side wall, forward side wall, lower back panel, and floor were constructed of light weight carbon fiber skin/Nomex ${ }^{\circledR}$ honeycomb core of $\sim 2.8 \mathrm{~cm}$ thickness. A single Nomex® honeycomb core, a double honeycomb core (two cells of half the total thickness with a parting sheeting between them), and the TeSS' Fibrelam ${ }^{\circledR}$ material were tested. The single and double cores' attenuation were essentially identical below $800 \mathrm{~Hz}$. The double core provided $\sim 1-3 \mathrm{~dB}$ greater attenuation above $800 \mathrm{~Hz}$. The Fibrelam ${ }^{\circledR}$ transmission was similar to the carbon fiber composites below $200 \mathrm{~Hz}$ but generally $5-20 \mathrm{~dB}$ less attenuation above $200 \mathrm{~Hz}$ compared to the carbon fiber/Nomex ${ }^{\circledR}$ composites. The single Nomex ${ }^{\circledR}$ core carbon fiber composite panels were selected because ease of manufacturer outweighed the minor acoustical benefit. The lowest transmission loss was $\sim 12 \mathrm{~dB}$ at $100 \mathrm{~Hz}$.

The CQ racks also incorporated $\sim 125 \mathrm{~kg}$ of ultra high molecular weight polyethylene for reduction of radiation material. The 6-cm thick panels are located in the pop-up ceiling, and back walls (except for the lowest panel). This material was selected for its radiation reduction properties. The lowest transmission loss was $\sim 12 \mathrm{~dB}$ at $100 \mathrm{~Hz}$.

The CQ rack bump-out is constructed primarily of aluminum ( $\sim 0.1-0.7 \mathrm{~cm}$ thickness) due to the many angles and internal attachment points. The aluminum exhibits little transmission loss below $300 \mathrm{~Hz}$. At $300 \mathrm{~Hz}$, the aluminum transmission loss is $\sim 7 \mathrm{~dB}$. Since the transmission losses below $300 \mathrm{~Hz}$ were so low, the bump-out's exterior acoustic blankets were incorporate acoustic barrier materials. 


\section{Acoustic Blankets}

As summarized in the preceding paragraph, the CQ rack bump does not provide much low frequency acoustic mitigation and a blanket is required. The blanket design had to balance flammability requirements, cleanability, and acoustics. Nomex ${ }^{\circledR}$ is often used in space applications because of its flammability resistance but it can retain stains, trap dirt, and be difficult to clean as was experienced in the TeSS acoustic blankets. Five fabrics (Nomex ${ }^{\circledR}$, Ortho fabric, a Teflon ${ }^{\circledR}$ fabric, and two Gore-Tex ${ }^{\circledR}$ fabrics) were evaluated for stain resistance and cleanability. Soiling was evaluated by combining elements from ASTM D4265, 'Standard Guide for Evaluating Stain Removal Performance in Home Laundering', AATCC Test Method 118-1983, 'Oil Repellency: Hydrocarbon Resistance Test', and AATCC Evaluating Procedure - Gray Scale for Staining.' The fabric samples were soiled with instant coffee (an ISS drink) and an oil to simulate human skin oils. The Gore-Tex ${ }^{\circledR}$ and Teflon ${ }^{\circledR}$ fabrics were substantially more resistant to staining than the Nomex ${ }^{\circledR}$ and Ortho fabrics. Additionally, the air permeability of the fabrics was evaluated using ASTM D737, 'Standard Test Method for Air Permeability of Textile Fabric.' Fabrics with higher air permeability allow more sound energy to transfer through to lower layers of sound adsorbing material. TeSS' Nomex ${ }^{\circledR}$ had the lowest air permeability of $2.0 \mathrm{~m}^{3} / \mathrm{hr}$ whereas the other materials ranged from $17-140 \mathrm{~m}^{3} / \mathrm{hr}$ depending on the material weave. Evaluation of the two tests resulted in the selection of a white Gore-Tex® fabric for the interior surface of the blankets. White Nomex ${ }^{\circledR}$ for the external surface next to the CQ structure was selected for its flammability resistance and relatively high stiffness to give the blankets 'body' during handling and installation. The primary sound blocker is Barium Impregnated Silicon Oxide (BISCO ${ }^{\circledR}$ ) elastomeric sheet, 1.2 $\mathrm{kg} / \mathrm{m}^{2}$. It provides a minimum of $11 \mathrm{~dB}$ reduction. A range of sound adsorbing interior materials were tested including: Nomex ${ }^{\circledR}$ Durette ${ }^{\circledR}$ felt (used on TeSS), Kevlar, and Thinsulate ${ }^{\mathrm{TM}}$. Initially Thinsulate ${ }^{\mathrm{TM}}$ was chosen because it was $26 \%$ lighter per unit area than Kevlar. However, Thinsulate ${ }^{\mathrm{TM}}$ unexpectedly failed the flame propagation test so it was replaced with Kevlar because it is lighter per unit area than Durette ${ }^{\circledR}$ felt. The CQ interior blankets are similar construction except the BISCO ${ }^{\circledR}$ is not required because the CQ structure provides adequate acoustic blocking. The final construction of the blankets is depicted in Fig. 12. From a usability perspective, the blankets were quilted to prevent billowing. $5-\mathrm{cm}$ by $5-\mathrm{cm}$ hook and loop fasteners patches are used on the backside to attach the blankets to the CQ structure and similar patches are used on the front to allow attachment of crew items. Grommets are used to reinforce mounting holes for D-rings that are used to hold crew items with elastic cords or ties. From a performance perspective the amount of thru stitching used for quilting and attachment hook-loop fasteners is minimized because it compresses the thickness which reduces acoustic adsorption. Quilting was limited to $\sim$ every $10 \mathrm{~cm}$ and the hook and loop fasteners were bonded to the fabric and corner stitched through the top fabric surfaces to minimize blanket compression, Fig 13.
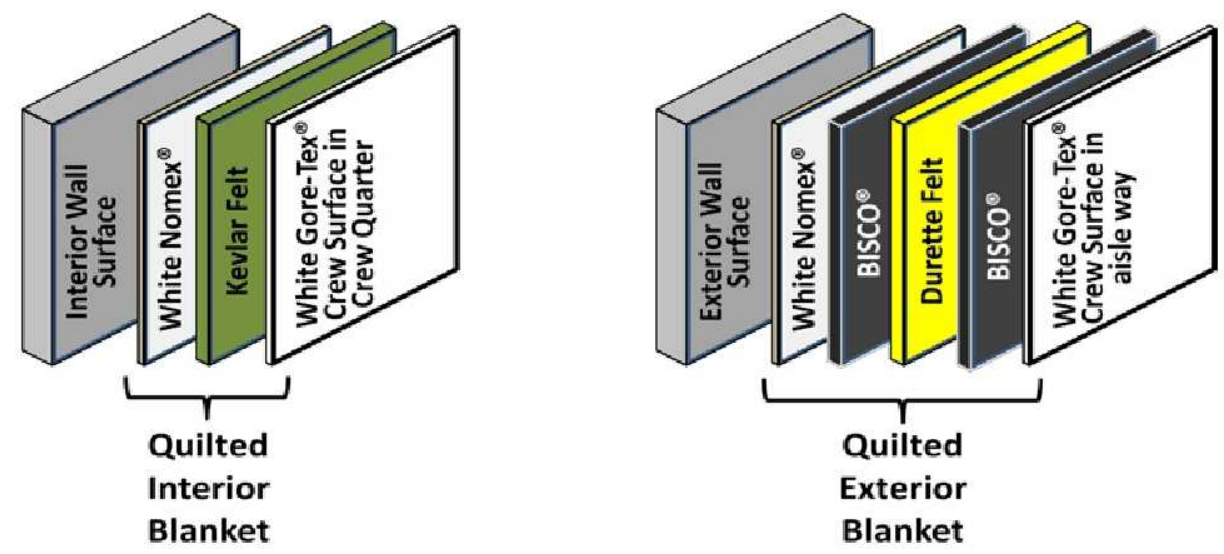

Figure 12. Interior (left) and exterior (right) acoustic blanket material lavers.

\section{Flight hardware implementation}

The CQ flight structure, electronics, and abatement design completion was later than planned and resulted in limited opportunity for full flight test of the integrated fan, abatement, and blanket testing. Additionally, program funding limits had removed the qualification CQ unit. As described above, this resulted in the mid-fidelity mockup's use being extended beyond the original planned crew uses. It was also used for testing portions of the blankets, fan operation, and duct abatements. 


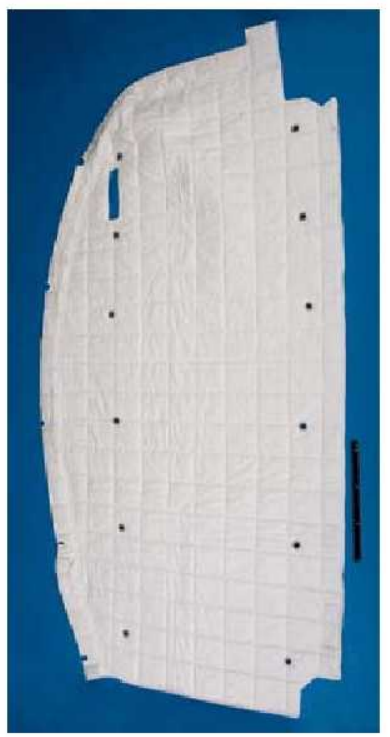

\section{Acoustic Blankets}

The three-dimensional external bump-out acoustic blanket was fit checked with the bump-out during its mechanical assembly. Likewise the interior blankets were test fit to the rack structure during assembly and revealed that several hook and loop fastener patches were not in proper alignment due to inadvertent mirror image differences between port and starboard configuration. These enabled minor adjustments to blanket patterns as all four CQs were being fabricated simultaneously. Despite acoustic testing to select lighter weight materials, the CQ blankets still weighed $\sim 23 \mathrm{~kg}$ per CQ and occupied $\sim 0.1 \mathrm{~m}^{3}$ of volume.

\section{E. Duct/Abatements Integration}

Figure 14 shows the CQ bump-out during final assembly without the interior acoustic blankets, close out panels, and antiblockage net. This configuration allows the majority of ventilation abatements to be visible. The gold surfaces are Durette ${ }^{\circledR}$ felt and have good air permeability characteristics. The abatement interior composition varies depending on the abatement piece, but typically contains an open cell polyimide foam external contoured shape and a Thinsulate ${ }^{\mathrm{TM}}$ batting interior. The olive

Figure 13. Typical CQ sleep wall

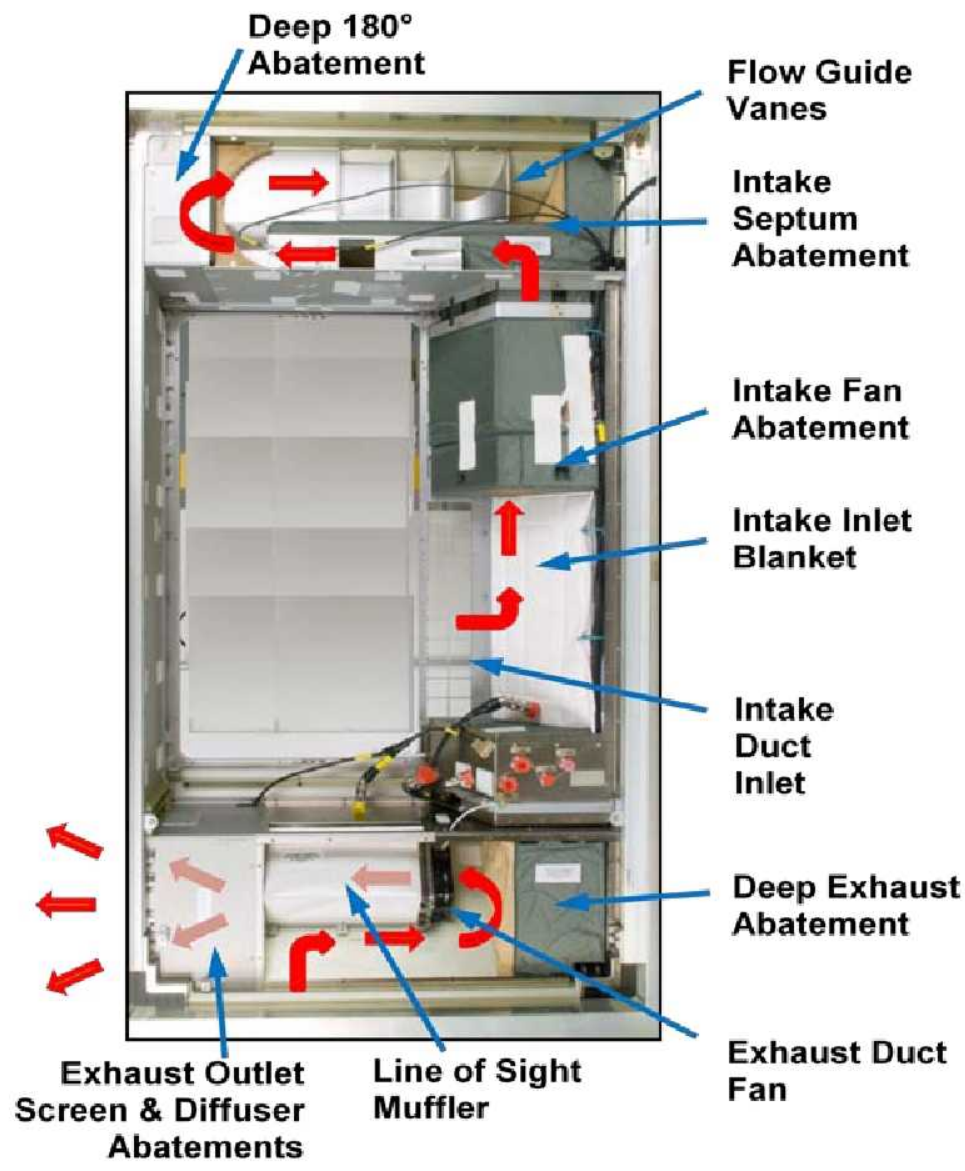

Figure 14. Bump-out interior with acoustic blankets and closeout panels removed to expose ventilation duct acoustic abatements.

The NC-40 limit for sleep environments was established as the level that is needed to provide auditory rest for the

abatements are held to the aluminum walls with a combination of hook and loop fasteners and light compression. All of the abatements are designed to be cleanable with the ISS vacuum cleaner outfitted with an upholstery brush attachment. The abatements can also be replaced if they are damaged or become unacceptability dirty.

\section{F. Certification Acoustic Testing}

Prior to final delivery, acoustic certification testing of the CQ rack was conducted to compare the acoustic performance with the requirements. Reiterating the CQ acoustic requirements include the exterior rack emissions, the minimum interior, and the maximum interior sound levels.

The ISS acoustic requirements for hardware and interior volumes were developed from experience gained during the Space Shuttle program and the NASA missions to the Russian Mir space station. The requirements are written in terms of noise criterion (NC) curves, which allow higher sound levels in the low frequency octave bands where human hearing is less sensitive. ${ }^{3}$ NASA habitability standards establish NC-50 as the acoustic work environment and NC40 as the limit for sleep environments. ${ }^{4}$ The NC-50 curve is the limit where $75 \%$ of conversation can be understood with a normal speaking level at 1.5 to $1.8 \mathrm{~m}$. 
crew to prevent stress, anxiety and to promote physical relaxation. Additionally the minimum requirement for the sleep environment is that the sound level must exceed NC-25. This minimum requirement was established due to feedback from the crew indicating that they wanted to hear the machinery operating in their vicinity so that they could subjectively tell if there was a malfunction based on the change in sound $\mathrm{d}^{5}$.

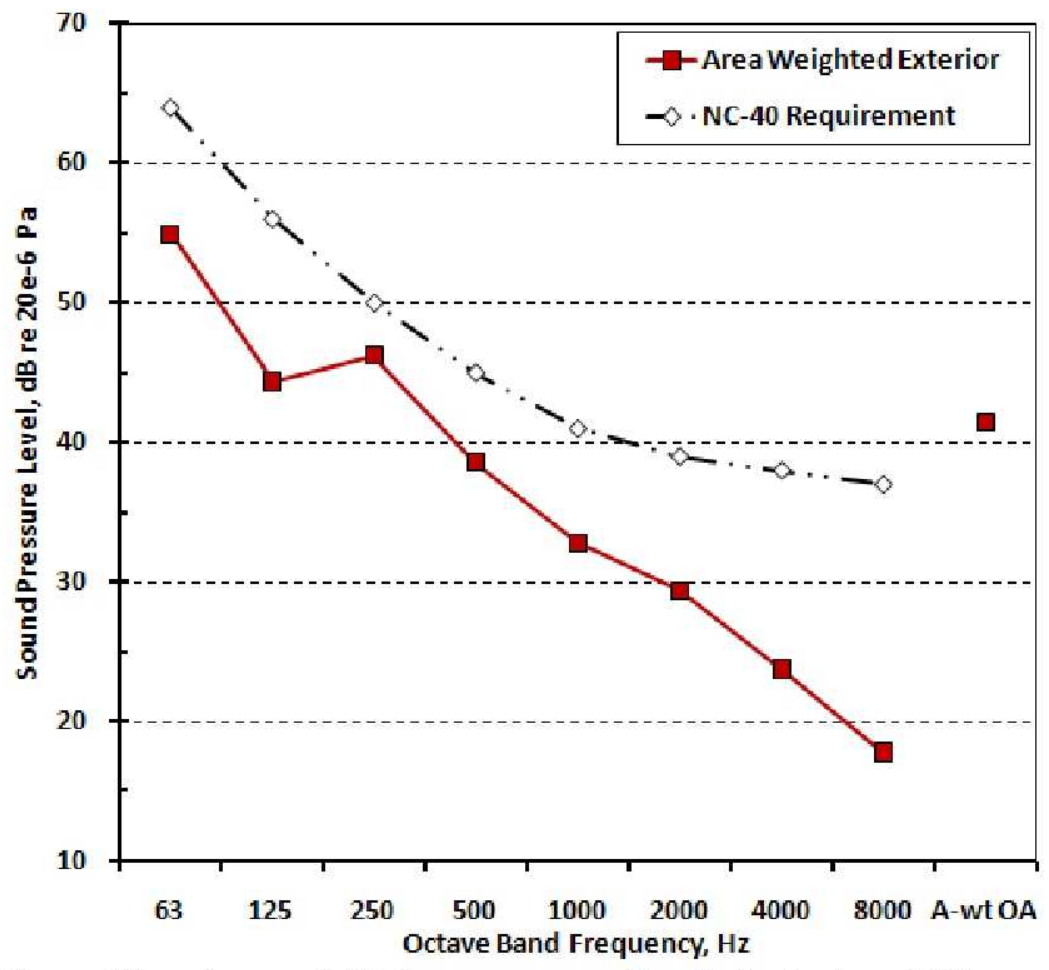

Figure 15. Area weighted average sound level of exterior of CQ.

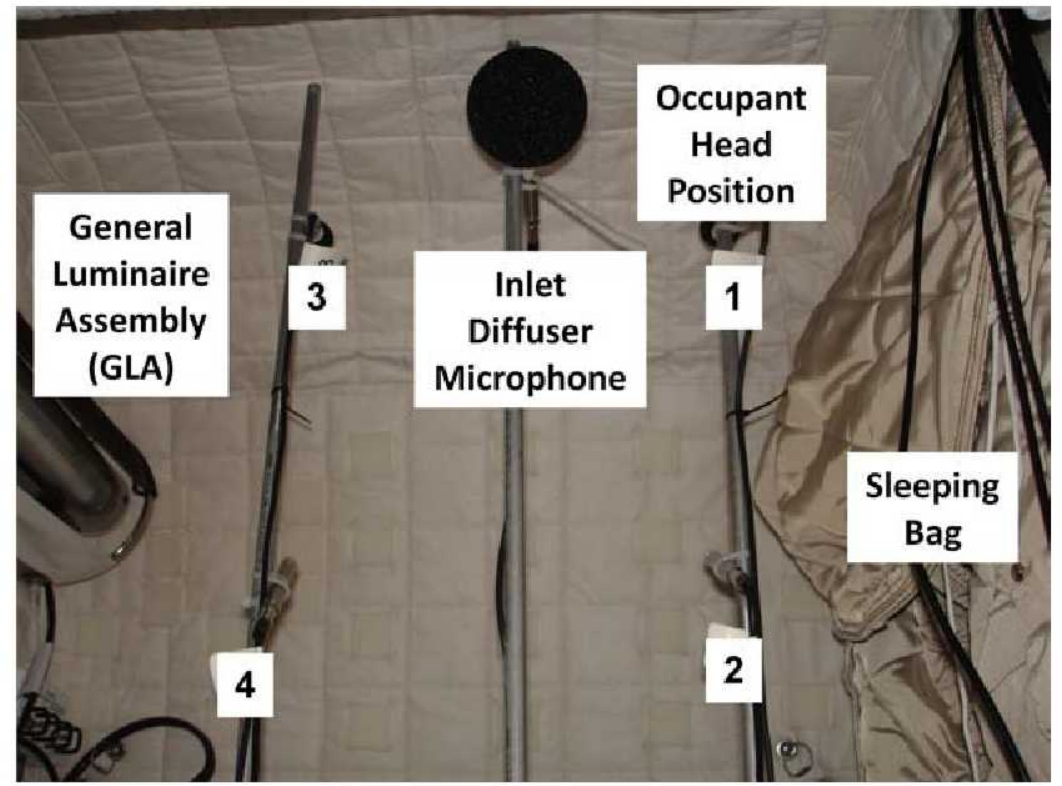

Figure 16. Photograph of the $C Q$ interior $30 \mathrm{~cm}$ measurement grid.
The CQ rack exterior continuous acoustic emissions requirement is that the levels are not to exceed the NC-40 octave band limits. This is a sub allocation of the overall Node 2 module to meet NC-50 when all the Node's hardware acoustic spectrums are integrated. Exterior emissions of the CQ rack were assessed using a spatially weighted average calculated from a 14 microphone array that was distributed across the front and sides of the bump-out structure. This method has been used before on other ISS rack systems. However, the CQ is the most complex geometry rack to date that the array method has been applied. From the measurements, it was determined that exterior noise level met the NC-40 requirements with the ventilation at the "low" speed setting, Fig. 15. This was considered acceptable because the "low" speed setting was considered the continuous operating condition. The higher settings were considered intermittent operating conditions.

The CQ interior sound level acoustic requirements are measured at the occupant head location are to be greater than NC-25 and not to exceed NC-40. The exterior sound level requirement also only applies at the low speed ventilation setting. The rational for this is that the crew has control of the ventilation speed and can adjust it to suit their personal preference. Therefore, the lowest ventilation setting is considered the nominal condition for this analysis.

The occupant head location was determined using the range between the $95^{\text {th }}$ percentile male and the $5^{\text {th }}$ percentile female. The occupant's zero-gravity neutral body posture limits the head position to within a 10 $\mathrm{cm}$ range. The midpoint of this range next to the side wall sleeping bag was used for the head location measurements.

Although the occupant head location was the only point dictated by the acoustic requirement, three other interior locations were also used in order to assess the overall interior sound field of the CQ rack, shown in Fig. 16.

11

American Institute of Aeronautics and Astronautics 


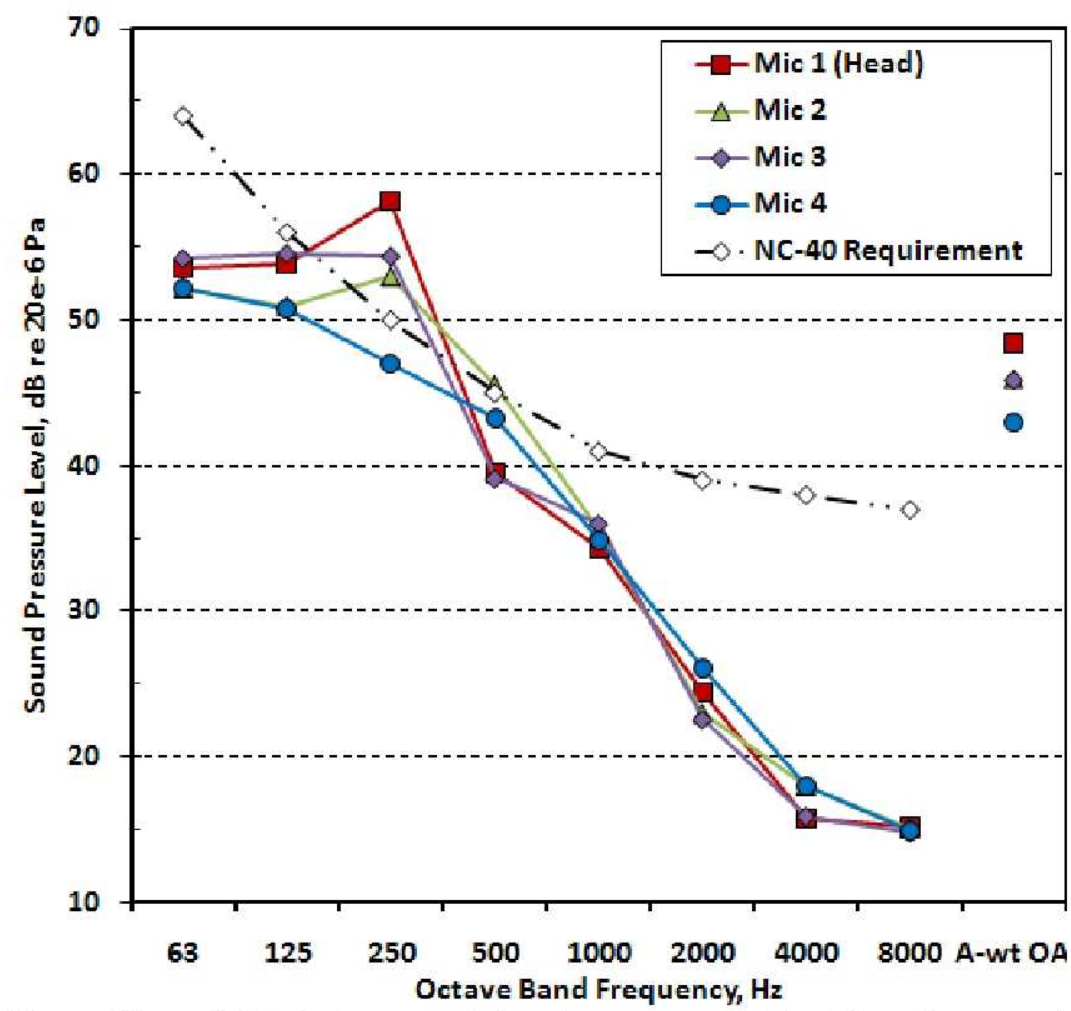

Figure 17. CQ interior sound level measurements at low fan speed from microphone array.
The octave band spectrum results for all four measurement locations are shown in Fig. 17. An exceedance to the acoustic requirement is noted in the $250 \mathrm{~Hz}$ octave band at the occupant head location. The frequency of the exceedance corresponds with the blade pass frequency of the inlet and exhaust fans and this band's levels were a challenge during the developmental acoustic testing. It is interesting to note the variation of the level of the $250 \mathrm{~Hz}$ octave band peak over the CQ volume. The level drops dramatically as the measurement location moves toward the center of the volume. This indicates that the geometry of the interior volume plays an important role in the amplification and attenuation of particular frequency content of an acoustic signal. On the basis of this large variation with measurement location, an exception to the acoustic requirement was granted.

\section{CQ On-orbit Performance}

\section{G. Crew Feedback}

Since the initial CQ installation in Dec 2008, six crew members have occupied the CQs. Crew privacy restrictions prevent the delineation of specific crew comments. However, in general crew feedback has been very favorable. The crew has indicated that overall volume, illumination, and stowage of the CQ are acceptable. There have been a few comments about the desire for a few more hook and loop fastener patches for display/placement of crew items. Adequacy of airflow has generally been acceptable with most crew members reporting that they kept the fan on low or medium speed. Since the interior temperature of CQ is dependent on the combination of the Node 2 CCAA temperature setting and the CQ fan speed setting, there have been times when one crew member is too warm while others are comfortable. Acoustically the crew recognizes that the CQ does provide a needed acoustic break from the ISS aisle ways and work areas. The interior does allow a quiet and dark place for sleeping. However, several crews have commented that the fan's high speed setting does generate a louder acoustical environment than desirable.

The only on-orbit issue has been the repeated triggering of the starboard CQ single fan failure alarm. The alarm can be triggered by either the intake or exhaust duct because the signals are logically 'OR'ed together. Troubleshooting to date has included limited crew inspection and air speed readings with a handheld meter in the CQ air outlets. With only limited crew time available for trouble shooting it has not been practical to get sufficient data to compensate for the variability caused by the relatively low air speed and turbulent divergent outlet airflow. Although inconclusive, the leading alarm trigger candidate is that dust has accumulated on both fans and or flow sensors and reduced the air flow. The CQ interior is vacuumed weekly including the inlet screens of both the inlet and exhaust ducts. Lint is reported to be present on the screens during the cleaning. Although the fans are cleanable, they are purposely located in the duct interiors and surrounded by acoustical abatements to reduce acoustical noise. The intake fan requires the removal of two panels and one abatement to access. The exhaust fan requires the removal of the antiblockage net and one panel to access. The CQ fans and ducts are scheduled to have their first disassembly and cleaning in April 2010. Based on this initial cleaning activity the frequency of cleaning will be adjusted in order to maintain adequate ventilation system performance. 


\section{H. Acoustic Measurements}

Acoustic measurement surveys of the ISS are conducted bi-monthly. Always of particular interest to these surveys are the sleep locations of the crew. Due to the short delivery schedule for the CQ racks, it was not possible to perform an acoustic test of the first two racks that were delivered to the ISS in late 2008 on flight ULF2. However, the CQ rack that acoustic certification testing was performed arrived in late 2009 on flight 17A. To date, all three units have been surveyed. Typical octave-band spectra of the three units measured at the occupant head location operating at low speed are shown in Fig. 18, as well as the ground test measurement results. Note the blue curve is the acoustic certification rack discussed previously.

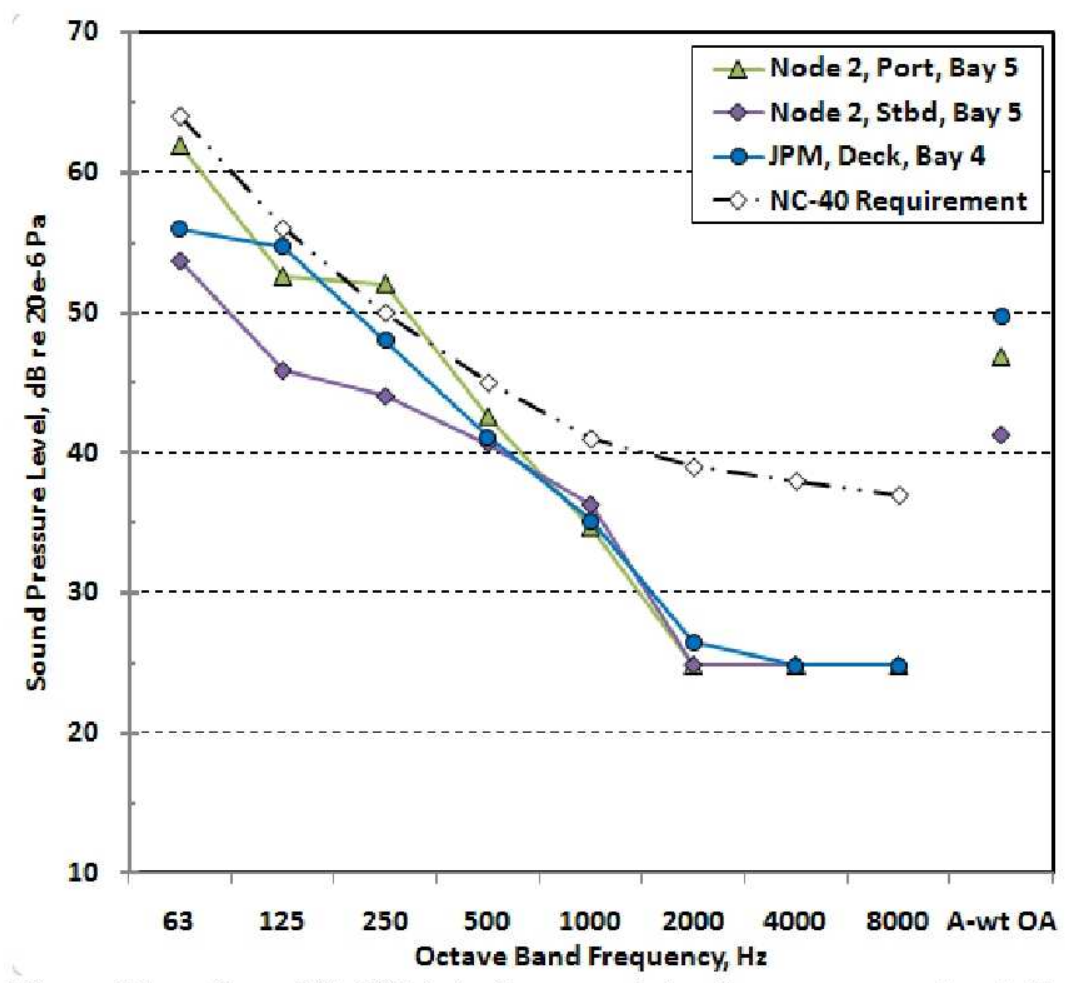

Figure 18. On-orbit CQ interior sound level measurements at the occupant head location with then fan on low fan speed.

The variation between the three units on-orbit is somewhat surprising, as well as the relatively low sound levels on-orbit as compared to the ground test. There are several possibilities for the variations between units and the ground testing. First, the microphone location is not as well controlled during the on-orbit as in the laboratory. The crew member performing the measurement is simply asked to place the microphone in the occupant head sleep position and take the measurement. Second, some variation was noted during the ground testing based on the assembly of the CQ structure and abatements. Since the racks were assembled on orbit on different occasions, it is not surprising that some variation between the acoustics of the racks would be noted. Finally, the decrease in levels as compared to the CQ ground testing is attributed to the deployment of crew personal effects (such as clothing) inside the rack. Acoustic tests performed during the development of the CQ indicated that the interior sound levels were very sensitive to the volume and absorption of items placed inside. However for to maintain repeatability, crew items were not accounted for in the certification test since they vary from crew-member to crew-member. Crew items that are installed on-orbit can include stowage bags for clothing, pictures, laptop, and other items.

\section{Conclusions}

In general, the ISS CQs have received favorable crew comments with respect to acoustics. Some crew comments have indicated the need for reducing the acoustic signature of fans on high speed. As demonstrated by the CQ hardware it is possible to reduce noise transmission from the relatively acoustically noisy ISS aisle way to provide a dedicated crew volume that is quite and private. The use of full scale functional ventilation/acoustic mockups is critical to successful implementation. However, this paper illustrates the significant design considerations, testing, and impacts required to reduce acoustic noise by $\sim 12 \mathrm{dBA}$ for a $2.1 \mathrm{~m}^{3}$ habitable volume. In addition to the development cost for acoustic reductions while providing adequate ventilation, the CQ had to allocate $\sim 13 \%$ and $\sim 6 \%$, respectively of its total mass and volume. The total impact across all four CQs is $\sim 91 \mathrm{~kg}$ and $1.1 \mathrm{~m}^{3}$. This is a significant penalty for passive noise cancellation for ISS which is in low earth orbit. Future missions at Lagrange points or planetary surfaces can likely not support this level of mass and volume impact. It would be beneficial to reduce noise at its source using advanced quite fans and active noise cancellation inside ventilation ducts. This would reduce the ambient acoustic noise of future vehicles and greatly reduce or eliminate the need for passive acoustic measures. 


\section{Acknowledgments}

This paper summarizes the hard work that was performed by numerous JSC NASA, Engineering Support Contract, Bioastronautics Contract, engineers, analysts, functional specialist, technicians, and crew members. The CQ project is funded by the NASA JSC ISS Vehicle Office.

\section{References}

${ }^{1}$ Broyan, J. L., Borrego, M. A., Bahr, J. F., "International Space Station USOS Crew Quarters Development," 2008-01-2026, $38^{\text {th }}$ International Conference on Environmental Systems, SAE International, Warrendale, PA, 2008.

${ }^{2}$ Broyan, J. L., Borrego, M. A., Bahr, J. F., "International Space Station USOS Crew Quarters On-orbit vs. Design Performance Comparison," 2009-01-2367, 39 ${ }^{\text {th }}$ International Conference on Environmental Systems, SAE International, Warrendale, PA, 2009.

${ }^{3}$ Beranek, L. L., Ver, I. V., "Noise and Vibration Control Engineering," John Wiley \& Sons, 2006.

"Man-System Integration Standard," NASA-STD-3000 vol. III, 1994.

${ }^{5}$ Goodman, J. R. "International Space Station Acoustics," NOISE-CON 2003, Institute of Noise Control Engineers, Indianapolis, IN, 2003. 